\title{
A Review of Squirrel Alarm-Calling Behavior: What We Know and What We Do Not Know About How Predator Attributes Affect Alarm Calls
}

\author{
Thaddeus R. McRae
}

Department of Natural Sciences, Lee University, Cleveland, Tennessee

Corresponding author (Email: thaddeus.mcrae@gmail.com)

Citation - McRae, T. R. (2020). A review of squirrel alarm-calling behavior: What we know and what we do not know about how predator attributes affect alarm calls. Animal Behavior and Cognition, 7(2), 168-191. doi: https://doi.org/10.26451/abc.07.02.11.2020

\begin{abstract}
Forty years ago, vervet monkeys were shown to use three different predator-specific calls that elicit three different antipredator behaviors, jump-starting investigation into the information content of animal signals. Over the intervening years, our thinking about the nature of alarm calls has continued to mature. Based primarily on studies in primates, squirrels, and birds, our conceptualization of alarms has moved from a dichotomous view of calls as either referencing external stimuli or expressing emotional response, toward an increasingly nuanced view of emotional and external contexts interacting in sometimes nuanced ways to shape communication. Simultaneously, after vigorous debate, the fundamental role of information in alarm calls, as in other forms of communication, is largely accepted. However, many core phenomena in alarm-calling behaviors remain unresolved. Among these, the forces that give rise to generalized alarms versus specialized categorical or continuous variation in alarm call acoustic parameters are not well characterized, in part because most alarm calling systems are either not so simply categorized or are themselves not yet well-understood. To move the field forward, we must better understand the layered information content of alarms, and how that information does and does not affect the behavior of others. With the goal of encouraging additional research in these areas, I summarize what we know and what we do not know about the predator-related information in squirrels' alarm calling systems across the five subfamilies of Sciuridae, in the context of their sociality and whether they are burrowing or arboreal.
\end{abstract}

Keywords - Alarm calls, Sciuridae, Animal communication, Referential, Information

Forty years ago, Seyfarth et al. (1980a, b) experimentally verified Struhsaker's (1967) observations that vervet monkeys use at least three acoustically distinct alarm calls, which are each associated with a distinct predator and elicit a distinct predator-specific response, even in the absence of any other cues to predator presence. This prompted on ongoing investigation into such 'functionally referential' alarm systems (Macedonia \& Evans, 1993). The concept of functionally referential signals and the notion of information in alarms has elicited some debate to which Seyfarth and Cheney and colleagues made key contributions (Macedonia \& Evans, 1993; Manser, 2013; Rendall et al., 2009; Scarantino \& Clay, 2015; Seyfarth \& Cheney, 2003, 2016; Seyfarth et al., 2010; Townsend \& Manser, 2013; Wheeler \& Fischer, 2012, 2015). This debate centered around whether the concept of information in animal communication was useful, with concern, as summarized by Rendall and colleagues (2009) that 'informational approaches' often leave the concept of information undefined and additionally place restrictions on the type of questions examined. The informal use of linguistic terms like 'meaning' can indeed be misleading and might suggest cognitive processes that cannot be extrapolated from the 
available data. The discourse resulted in a clarification of the concept of information in much of the literature. I suggest that, today, the concept of information in animal communication may be most usefully defined simply as an association between some property of a signal and some property external to the signal (but not necessarily external to the signaler).

It is also true that there are many enlightening investigations into animal communications, such as alarm calls, that can be pursued without directly considering information content. For example, looking at behavioral responses to an alarm call by conspecifics, predators, and heterospecific eavesdroppers can reveal ecological function of signals and their fitness implications. However, there is some consensus around the fact that, for communication to occur, for any animal signal to affect another individual, there must be some information contained in the signal, which is otherwise random noise and therefore not useful. Investigating various layers of information content in signals, including alarm calls, will be vital, if not always central, to understanding signal function, form, and evolution.

Although alarm signals are defined by their association with the presence of a predator, sometimes signals initially identified as alarm signals are also used in other contexts. This broader use of such calls suggests that information on predator presence can be a by-product of an association between the presence of certain predators and the presence or degree of one or more internal states (e.g., fear and aggression) that also occur in non-predator contexts. Darwin (1872) observed that apparently emotional behavior can have intelligible functions. For example, standing tall and baring teeth in an aggressive dog prepares the dog to attack, while communicating both its emotion of aggression and that it is likely to attack. Indeed, upon reflection, there is perhaps very little distinction between an emotion and a particular set of behavioral probabilities. Morton's (1977) motivational-structural rules suggested that the acoustic structure of vocalizations given in various external contexts is strongly influenced by a caller's internal state along axes of hostility and of fear or appeasement. Seyfarth and Cheney (2003) acknowledged the intertwined effects of emotion and external context on shaping calls. Gensini (2020) recently summarized the growing convergence of approaches considering symbolic and emotional views of communication and observed that more unified views are increasingly common.

It is clear that internal and external states can simultaneously affect signaling behavior, but this does not limit calls' ability to contain useful information about predators and other external factors. Even a hypothetical set of calls based solely on degree of fear would contain reliable information on predator presence if certain degrees of fear are reliably elicited by certain types of threats. Such associative information is likely the basis for much eavesdropping between species, which is often learned behavior based on the reliability of information that a caller provides a particular heterospecific listener (Magrath et al., 2009). Regardless of a signal's intraspecific function, eavesdroppers can use any relevant information in an overheard signal, as in gray squirrels (Sciurus carolinensis) that reduce anti-predator behavior when they hear avian contact calls (Lilly et al., 2019).

So, while there is much to be done exploring the various forces that determine the structure and function of alarm calls, much of our current knowledge centers on the information, or lack thereof, in alarms about external context, which has appropriately been the focus of much research over the last four decades. Much insight into ecology, behavior, and sometimes cognition can be gained by examining the various information in the calls, and how well calls predict behaviors of conspecifics and heterospecifics, including predators, hearing the calls. The information content of a call, in terms of the degree of association between call parameters and some other variable (e.g., presence of a predator), serves as an upper limit on the ability of a call to affect behavior of others in a manner associated with that variable. This is true regardless of caller intent or cognitive processes. Here, with the goal of encouraging further research on the themes summarized above, I attempt to summarize the current state of our understanding of the information about predators in sciurid alarm calls. To do so, I worked systematically through the phylogeny of all identified sciurids, searching the literature on each genus within Sciuridae for any publications mentioning alarms and using species names (including historical synonyms) when many results were returned for a genus.

Based on whether trees or burrows are used as shelter, sciurids can be loosely categorized as tree squirrels or ground squirrels, with ground squirrels deriving from the arboreal ancestral state and 
arboreality having a strong phylogenetic signal, with all ground squirrels belonging to two clades within Xerinae (Mercer \& Roth, 2003; Steppan et al., 2004, Figure 1). The significant risk posed by specific aerial and terrestrial predators and the use of both ground and trees as foraging space makes tree squirrels, in particular, a phylogenetically distant but behaviorally parallel group to arboreal primates when it comes to predator avoidance.

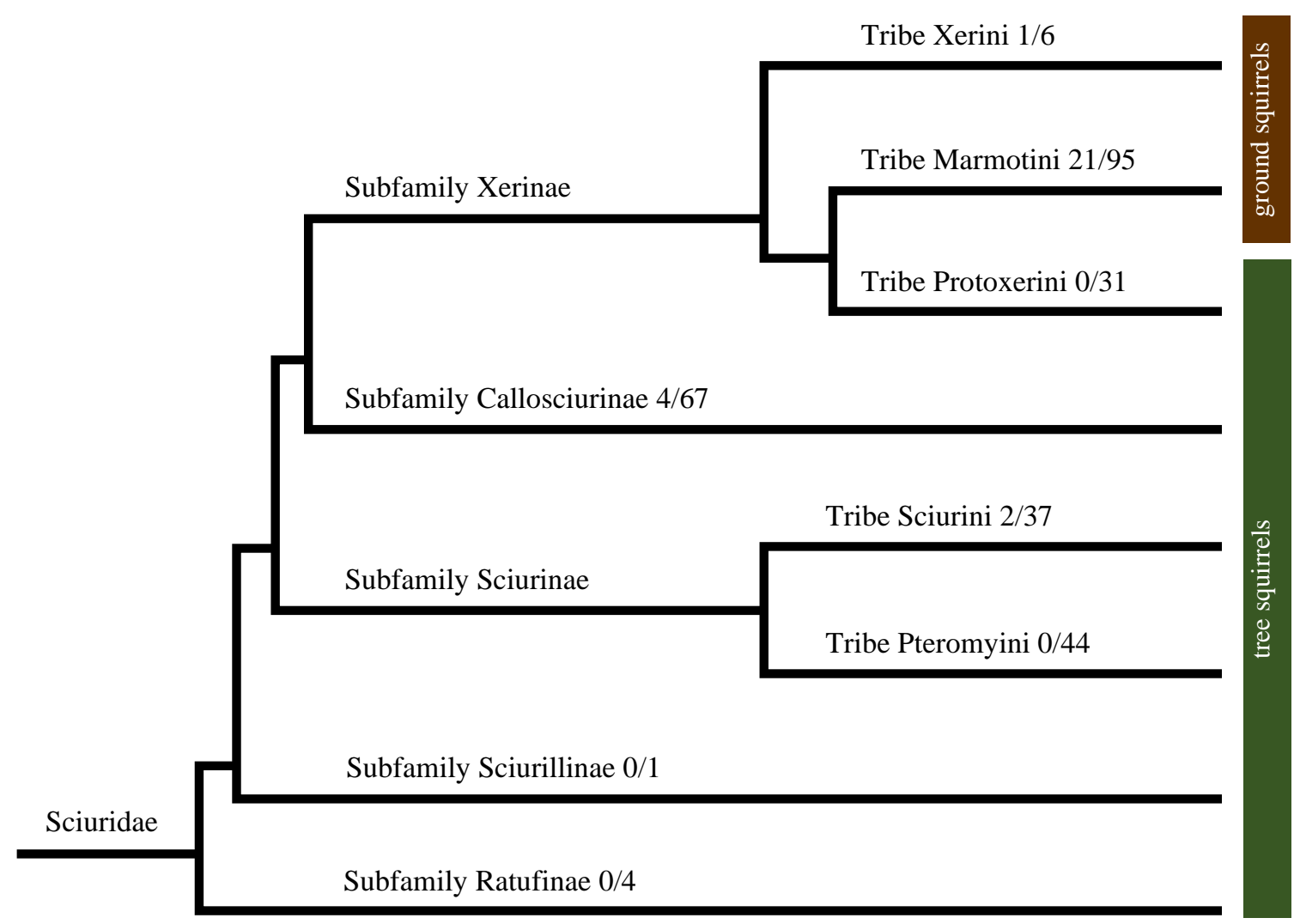

Figure 1. Phylogeny of Sciuridae (Steppan et al., 2004) with number of species where any of the predator information in their alarm calls has been studied, followed by the total number of species.

\section{Alarm Signals in Ground Squirrels}

Over the last several decades, many studies have focused on the alarm calling systems of ground squirrels. California ground squirrels (Spermophilus beecheyi), Belding's ground squirrels (Spermophilus beldingi), eastern chipmunks (Tamias striatus), and some other ground squirrels have been shown to use different alarm calls for terrestrial/mammalian versus aerial/avian predators (Table 1). In at least some of these species, however, the difference is interpreted as due to urgency, usually defined as distance of threat from caller or suddenness of its approach, rather than categorical classification of threats as terrestrial or aerial. In Table 1, I have listed the specificity of alarm call production in each species, based solely on whether a relationship exists between call type or some acoustic parameter and predator type or urgency. In several cases, alarm calls differ in a single parameter based on both predator type and urgency. Experimental presentations of aerial and terrestrial stimuli that also differ in approach distance, speed, or angle could tease apart the roles of predator type and predator distance or other indicator of urgency. It is also possible that predator taxon is simply another category of urgency or level of danger. As summarized for representative species below, there is much that remains unknown about the interplay of predator taxon, location, movement, etc., in shaping alarm calls and the resulting responses to alarm calls. Below I describe what is known about alarm calling in a selection of the most studied ground squirrel species for which data on alarm call use is available, additional species are listed in Table 1. 
McRae 171

Table 1

Information About Predator Type in Mammalian Alarm-calling Systems that have been Examined for Specificity, with a Focus on Sciurids.

Species \& Sociality

$1=$ individual territories

$2=$ overlapping home ranges

$3=$ stable groups

Rodentia

Sciuridae

Xerinae (Marmotini)

Cynomys gunnisoni, 3

Cynomys leucurus, 3

Cynomys ludovicianus, 3

Cynomys mexicanus, 3

Cynomys parvidens, 3

Ictidomys tridecemlineatus, 3

Marmota bobak, 3

Marmota caligata, 3

Marmota caudata, 3

Marmota flaviventris, 3

Marmota marmota, 3

Marmota olympus, 3

Marmota vancouverensis, 3

Otospermophilus beecheyi, 3

Otospermophilus variegatus, 3

Tamias striatus, 1, 2

Urocitellus armatus, 3

Urocitellus beldingi, 3

Urocitellus columbianus, 3

Urocitellus richardsonii, 3

Urocitellus undulatus, 3

Xerinae (Xerini)

Atlantoxerus getulus, 3

Xerinae (Protoxerini)

Callosciurinae

Callosciurus caniceps, 2

Callosciurus erythraeus, 2

Callosciurus nigrovittatus, 2

Callosciurus notatus, 2

Sciurinae (Sciurini)

Sciurus carolinensis, 2

Tamiasciurus hudsonicus, 1

Sciurinae (Pteromyini)

Sciurillinae

Sciurillus pusilius, 2, 3

Ratufinae

\section{Carnivora}

Viverridae

Suricata suricatta, 3

\section{Primates}

Lemuridae

Lemur catta, 3

Varecia variegata, 3

Eulemur fulvus rufus, 3

\author{
Information found in calls \\ \& type of study \\ $\mathrm{O}=$ observational study ${ }^{\mathrm{a}}$ \\ $\mathrm{E}=$ experimental test
}

\begin{tabular}{lll}
$\begin{array}{l}\text { Conspecifics' } \\
\text { responses }\end{array}$ & Refuge & Source \\
$\begin{array}{l}\text { differ based } \\
\text { on call type? }\end{array}$ & $\begin{array}{l}\mathrm{A}=\text { arboreal } \\
\mathrm{B}=\text { burrow }\end{array}$ \\
\hline
\end{tabular}

unclear $^{\mathrm{b}}, \mathrm{E}$

unclear, $\mathrm{E}$

unclear, E

unclear, E

unclear, $\mathrm{E}$

urgency ${ }^{\mathrm{f}}, \mathrm{E}$

urgency, E

terrestrial/aerial, or urgency, $\mathrm{E}$

urgency, $\mathrm{E}$

urgency ${ }^{\mathrm{d}}, \mathrm{E}$

terrestrial/aerial, urgency, E

urgency, E

terrestrial/aerial, or urgency, E

terrestrial/aerial, or urgency, $\mathrm{E}$

urgency, $\mathrm{O}$

terrestrial/aerial/chase, $\mathrm{O}$

urgency in call rate, $\mathrm{E}$

terrestrial/aerial, or urgency, $\mathrm{O}$

terrestrial/aerial, or urgency, $\mathrm{E}$

urgency, $\mathrm{E}$

urgency, E

terrestrial/aerial, O

no specificity detected, E

terrestrial/aerial, $\mathrm{O}$

bird/cat/snake, $\mathrm{O}$

snake mobbing calls, $\mathrm{O}$

terrestrial/aerial calls, $\mathrm{O}$

terrestrial/aerial calls, $\mathrm{O}$

terrestrial/aerial, E

unclear, E

unclear, $\mathrm{O}$

terrestrial/aerial/snake,

plus urgency for each

terrestrial/aerial, E

urgency, $\mathrm{E}$

terrestrial/aerial $^{\mathrm{g}}, \mathrm{E}$
A

A

yes

B

$\begin{array}{lll}-\mathrm{c} & \mathrm{B} & 1 \\ - & \mathrm{B} & 2 \\ - & \mathrm{B} & 3 \\ - & \mathrm{B} & 2 \\ - & \mathrm{B} & 2 \\ \text { yes } & \mathrm{B} & 4 \\ - & \mathrm{B} & 5 \\ \text { yes } & \mathrm{B} & 6 \\ \text { no } & \mathrm{B} & 7 \\ \text { yes } & \mathrm{B} & 8 \\ \text { no } & \mathrm{B} & 9 \\ \text { yes } & \mathrm{B} & 6 \\ \text { yes } & \mathrm{B} & 6 \\ \text { yes } & \mathrm{B} & 10 \\ - & \mathrm{B} & 11 \\ \text { no } & \mathrm{B} & 12 \\ \text { yes } & & \\ - & \mathrm{B} & 13 \\ - & \mathrm{B} & 14 \\ \text { yes } & \mathrm{B} & 15 \\ \text { yes } & \mathrm{B} & 16 \\ - & \mathrm{B} & 17\end{array}$

no

A

21

19

19

19

1

A

$-\quad \mathrm{A}$

$\begin{array}{lll}\text { yes } & \text { A } & 25\end{array}$

$\begin{array}{lll}\text { yes } & \text { A }\end{array}$ $\begin{array}{lll}\text { yes } & \text { A } & 25\end{array}$ 


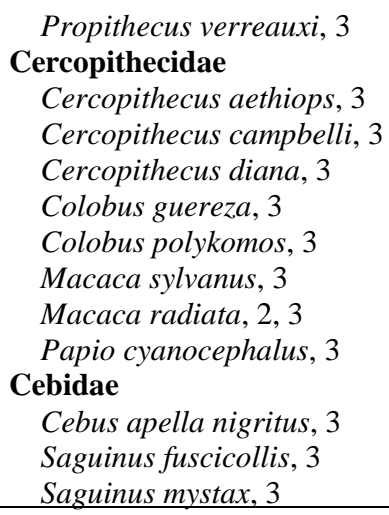

\begin{tabular}{|c|c|c|c|}
\hline terrestrial/aerial $^{\mathrm{g}}, \mathrm{E}$ & yes & A & 26 \\
\hline leopard/eagle/snake, E & yes & $\mathrm{A}^{\mathrm{h}}$ & 27 \\
\hline leopard/eagle, E & yes & A & 28 \\
\hline leopard/eagle, E & yes & A & 29 \\
\hline leopard/eagle, E & yes & A & 30 \\
\hline leopard/eagle, E & - & A & 30 \\
\hline person/dog i, E & - & A & 31 \\
\hline leopard/python ${ }^{\text {i }}, \mathrm{E}$ & - & A & 32 \\
\hline carnivore/crocodile, $\mathrm{O}$ & - & $\mathrm{A}^{\mathrm{h}}$ & 33 \\
\hline aerial/terrestrial/urgency, E & yes & A & 34 \\
\hline terrestrial/aerial, E & yes & A & 35 \\
\hline terrestrial/aerial, E & yes & A & 35 \\
\hline
\end{tabular}

Note: No data on alarm call specificity to predator context (urgency, taxon, size, location, etc.) are available for Sciurids not listed here. Differences in response based on call type recorded here may be either quantitative or qualitative. A dash means no data are available.

${ }^{a}$ Observational, as used here, refers to purely descriptive data with no statistical test of alarm call production specificity, regardless of sample size. Experimental refers to natural observations or experimental manipulations that produce data that are analyzed statistically for the presence of threat-specific alarm calls.

${ }^{\mathrm{b}}$ Specificity, while reported as high, is based on subtle changes in harmonic structure within a single acoustic class of alarm call and may be confounded by individual identity of each caller. There is no test of a specific response variable, or of same caller under two or more conditions.

${ }^{\mathrm{c}}$ They demonstrate that alarms differ by predator type, and response differs by predator type, but they do not test whether response differs by alarm call type.

dUrgency is coded in call rate, not call type; $96.46 \%$ of calling bouts consisted solely of "whistles."

e Alarm calls were frequently given to terrestrial predators, but rarely toward aerial predators.

${ }^{\mathrm{f}}$ These species showed mixed specificity, with specific calls for aerial threats, but the call given to terrestrial threats was also used in some aerial predator and non-predator contexts. They responded differently to the call types.

$\mathrm{g}$ Vervets and baboons may retreat to trees or rocky outcroppings but are not arboreal. Fleeing up a tree is not always the expected escape response, especially in baboons.

${ }^{\mathrm{h}}$ No aerial threats were tested.

Sources: 1 (Furrer \& Manser, 2009; Loughry, Oeser, Anderson, et al., 2019; Placer \& Slobodchikoff, 2000; Slobodchikoff et al., 2009) 2 (Frederiksen, 2005) 3 (Frederiksen \& Slobodchikoff, 2007) 4 (Schwagmeyer, 1980; Schwagmeyer \& Brown, 1981) 5 (Nikol'skii, 2000) 6 (Blumstein, 1999) 7 (Blumstein \& Arnold, 1995) 8 (Blumstein \& Armitage, 1997a) 9 (Blumstein \& Arnold, 1995; Boero, 1992) 10 (Boellstorff \& Owings, 1995; Leger \& Owings, 1978; Owings \& Leger, 1980$)$ 11 (Krenz, 1977) 12 (Burke da Silva et al., 1994; Getty, 1981; Weary \& Kramer, 1995) 13 (Balph \& Balph, 1966) 14 (Leger et al., 1984; Robinson, 1980) 15 (Harris et al., 2010; MacWhirter, 1992) 16 (Davis, 1984; Sloan et al., 2005; Warkentin et al., 2001) 17 (Melchior, 1971) 18 (van der Marel et al., 2019) 19 (Tamura \& Yong, 1993) 20 (Tamura, 1989, Tamura, 1995; Tamura et al., 1989) 21 (McRae \& Green, 2014, 2017) 22 (Digweed \& Rendall, 2009, 2010; Greene \& Meagher, 1998) 23 (Emmons \& Feer, 1997; Jessen et al., 2013) 24 (Manser, 2001; Manser et al., 2001) 25 (Macedonia, 1990) 26 (Fichtel \& Kappeler, 2002 ) 27 (Seyfarth et al., 1980a, b) 28 (Zuberbühler, 2001) 29 (Zuberbühler, 2000) 30 (Schel et al., 2009, 2010) 31 (Fischer, 1998; Fischer et al., 1995) 32 (Coss et al., 2007) 33 (Fischer et al., 2001) 34 (Wheeler, 2010) 35 (Kirchhof \& Hammerschmidt, 2006)

\section{Alarms in Xerinae, tribe Marmotini (Holarctic ground squirrels)}

\section{Yellow-Bellied Marmots (Marmota flaviventris)}

Yellow-bellied marmots are described as using three call types: whistles, trills, and chucks. In a study testing for context-specific alarm calls, Blumstein and Armitage (1997a) found 96\% of calling bouts contained only whistles. They observed chucks in only five of 537 calling bouts, and chucks were always followed by whistles. Trills were observed only 14 times and were preceded by whistles. Blumstein and Armitage (1997a) focus their analysis on whistles in response to five stimuli: people, dogs, a robotic taxidermic badger mount, eagles, and a model eagle. Several acoustic variables of whistles in response to the dog differed from whistles in response to the other four stimuli. Blumstein and Armitage 
(1997a) conclude that the variation is primarily a function of risk, with dogs representing a higher risk than any other stimulus used in the study.

From approximations based on the summary data in the report of Blumstein and Armitage (1997a), dogs elicited trills $19 \%$ of the time, compared with about $3 \%$ of the time in response to the badger mount, $3 \%$ of the time to people, and never to the model eagle. Of the 13 calling bouts with trills that also had a known stimulus, all were in response to terrestrial threats, but those threats included real and model predators as well as aggressive conspecifics. Trills were never used in response to an actual eagle or model eagle or other aerial stimuli (Blumstein \& Armitage, 1997a). Trills may be a call expressing extreme urgency or risk, but the possible specificity of trills to terrestrial threats deserves further study. Although the function of trills and chucks remains unclear, playback of recorded yellowbellied marmot whistles elicited antipredator behavior in conspecifics, and response differed based on the number of calls (single versus four), but not rate (number of calls/total bout length). Whistles also elicited more intense responses than chucks. It may be that yellow-bellied marmots do not have multiple predator escape strategies, and so they signal only degree of risk, not predator type. Based on observed behaviors in response to alarm calls, potential differences in predator-avoidance strategies seem limited to the posture while scanning (all fours or upright on hind legs only) and whether they descend into a burrow or stay at the surface. Additional studies manipulating risk (distance, speed of approach, etc.) within stimulus type could verify whether whistle use varies primarily with degree of risk.

\section{Other Marmots (Marmota spp.)}

Although yellow-bellied marmots seem to have a risk-based alarm calling system with one main call type, a later study of Olympic (M. olympus), hoary (M. caligata), and Vancouver Island marmots ( $M$. vancouverensis) found that they all used at least four acoustically distinct vocalizations during alarm calling bouts (Blumstein, 1999). Again, they appear to primarily communicate risk, mainly reflecting distance, but hoary and Vancouver Island marmot alarms also contained information about terrestrial versus aerial threat type. Playback experiments found no difference in response when testing call type, suggesting that they do not make use of any information about predator type. Interestingly, risk is coded using different acoustic features in each species. Similarly to these three North American species, the steppe marmot (M. babok) has been shown to vary call rate based on distance to a threat in space and time (Nikol'skii, 2000).

\section{California Ground Squirrels (Otospermophilus beecheyi)}

California ground squirrels use three acoustically distinct alarm calls in response to predators. Whistles are common in response to aerial predators, whereas chatters and chats are used in response to large mammalian predators (Owings \& Virginia, 1978). Comparing responses to whistles versus chatters and chats, Owings and Leger (1980) found that whistles were less likely to elicit upright scanning, and squirrels more quickly resumed normal feeding behavior, whereas chatters and chats elicited upright scanning with antipredator behaviors continuing for a longer period. These different responses could be adaptations to predator type. For example, low-flying raptors quickly pass through an area, and keeping a low profile may help ground squirrels avoid predation (Leger \& Owings, 1978). Similarly, immediate upright scanning that persists for a longer time may be well suited to avoid terrestrial predators, which are more likely than aerial predators to be hidden by objects on the ground, to move more slowly, and to linger in the area (Leger \& Owings, 1978).

Although there is a pattern of production and response based on aerial versus terrestrial predator type, the use of whistles versus chatters and chats can also be interpreted as a risk- or urgency-based alarm system. In this view, whistles are less intense alarms that elicit low-intensity antipredator behavior that quickly fades away, whereas chatters and chats are high-intensity alarms that elicit stronger antipredator behavior that persists. A later study examining chatter vocalizations in more detail showed that acoustic parameters of chatters differed among aerial predators, terrestrial predators, and aggressive 
conspecifics (Owings \& Leger, 1980). Within terrestrial predators, chatters by California ground squirrels also differed in response to snakes versus mammalian predators (dog, badger, and coyote). It is also likely that urgency and type of threat covary, and California ground squirrels may categorize threat types based on any combination of a predator's physical appearance or terrestrial versus aerial approach. Mantor (2012) notes that the first vocalization differs from consecutive vocalizations and may have a different function.

California ground squirrels do have distinct responses to rattlesnakes versus other terrestrial predators. Rather than retreating, they approach the snake, sometimes vocalizing, and usually tail flagging, which serves as a predator deterrent (Barbour \& Clark, 2012; Coss \& Owings, 1977). While the tail flagging function and differences in infrared signal based on snake type have been well-studied, (Rundus et al., 2007; ) it seems that the production patterns and effects of the associated mobbing calls are not well understood.

\section{Rock Squirrels (O. variegatus)}

A descriptive study of the rock squirrel tested for but did not observe a snake-specific call when presenting nine individuals with a caged snake. In natural contexts, two other alarm calls were observed, long and short alarms. Both consisted of a whistle and chucks, with short calls containing fewer chucks and having a lower fundamental frequency. Context of long alarms was undescribed, but short alarms either followed long alarms or were elicited by both passing hawks and large non-predatory land animals (Krenz, 1977). The descriptions of conspecific response to both calls suggest they first orient toward the caller, then toward the direction of the caller's orientation. After the initial response of running to the mouth of their burrow, additional anti-predator responses such as diving down a burrow were elicited only after conspecifics had first located the threat visually (Krenz, 1977).

\section{Eastern Chipmunks (Tamias striatus)}

Eastern chipmunks use three distinct call types: chips, chucks, and trills. Chips are highest in pitch, repeated, with a descending tone, and were elicited only by mammals or unidentified stimuli. Chucks are lower in pitch and were elicited only by birds, a moving hawk model, or unidentified stimuli (Burke da Silva et al., 1994). A playback study found chucks and chips elicited similar responses, but higher rates of calling and multiple sources of calls both elicited longer alert responses and increased probability of fleeing (Weary \& Kramer, 1995). These results suggest that there is information about whether a predator is a bird versus mammal and about urgency. Chips given in response to mammalian predators may additionally serve a predator-deterrence function (Bonenfant, 1996; Burke da Silva, 1993). Trills are used more often when kin are likely to hear but may also have a startle effect on predators pursuing a trilling chipmunk (Bonenfant, 1996). It is notable that eastern chipmunks live in forest habitats and differ from many ground squirrels in having a highly obstructed view of their environment, including the sky.

\section{Richardson's Ground Squirrels (Urocitellus richardsonii)}

Richardson's ground squirrels use two primary vocalizations, whistles and chirps. Initially, their alarms were interpreted as predator specific, with whistles in response to terrestrial predators and chirps to aerial predators (Davis, 1984). The level of production specificity was extreme, with no apparent crossing of alarm calls between predator types. Receivers also appeared to respond in unique ways to each alarm call, suggesting a functionally referential system that allowed receivers to use the appropriate strategy for terrestrial or aerial predators simply by hearing the alarm call. Ninety percent of the time, Richardson's ground squirrels ran to their burrow in response to chirps, the putative aerial predator alarm. In response to whistles, the putative terrestrial predator alarm, squirrels stood erect in place and fled only if the threat 
approached them closely (Davis, 1984). This result suggested that the ground squirrels used two incompatible strategies in response to terrestrial versus aerial predators.

Davis' (1984) study seemed to provide clear evidence for predator-specific alarms; later studies, however, revealed exceptions to the pattern that change the interpretation. Sloan et al. (2005) presented Richardson's ground squirrels with a hat thrown through the air, which elicited both chirps and whistles. They interpret the alarms as carrying information about the immediacy and ephemerality of a threat; perhaps immediate and ephemeral threats elicit chirps, whereas sustained threats elicit whistles. Because only a single stimulus was used in the experiment and because it resembles an aerial predator only in movement, it is difficult to compare these results to those of Davis (1984).

Warkentin et al. (2001) had previously used the same model of hat and found that individuals' alarm-calling rate negatively correlated with distance to the threat, possibly indicating risk or urgency in the perception of receivers. Warkentin et al. (2001) also observed that $92 \%$ of callers began their repetitive calls with whistles, which fits with Davis' interpretation of whistles as a response to aerial threats, if the hat is perceived as an aerial threat. Certainly, there is information about the aerial or terrestrial nature of the threat in call type and call rate of repeated calls carries information about distance of threat. The alarm calls of Richardson's ground squirrels seem to comprise a system where both predator type and urgency are encoded in different call attributes, although it is not yet clear how differences in response should be interpreted. Future studies using aerial and terrestrial stimuli approaching with similar speed, distance, and angle of approach relative to caller could clarify the roles of risk and predator type in eliciting whistles and chirps. Further, varying the manner of approach within terrestrial and aerial presentations could also tease apart the role of risk in combination with predator type.

Although other ground squirrel species may occasionally have ultrasound components to their alarms (Matrosova et al., 2012) and most species have not been tested for ultrasonic calls, Richardson's ground squirrels are the only ground squirrels verified to use a call that is purely ultrasonic; their "whisper" call is a flat narrow-band call at around $50 \mathrm{kHz}$ (Wilson \& Hare, 2004). This ultrasonic call is used more frequently for distant than to nearby stimuli (Wilson \& Hare, 2006), but its function relative to the lower-frequency whistles and chirps is not clear.

\section{Other Ground Squirrels (Urocitellus spp.)}

Four other species of Urocitellus ground squirrels have been observed to use alarm calls that differ based on urgency (Table 1) (Furrer \& Manser, 2009; Komarova et al., 2014; Loughry, Oeser, Anderson et al., 2019; Placer \& Slobodchikoff, 2000; Slobodchikoff et al., 2009). Of these, three have been observed to use calls that also differ in response to aerial versus terrestrial predators, but it is unclear whether this is simply a case of urgency differing between these two classes of predator.

\section{Gunnison's Prairie Dogs (Cynomys gunnisoni)}

When it comes to alarms that contain information about specific attributes of a threat, some work has suggested that alarms of Gunnison's prairie dogs carry more detailed information than has been demonstrated for any other mammals examined to date. Although there are no tests comparing use of categorical call types, Gunnison's prairie dogs have been shown to vary acoustic attributes of alarm calls elicited by different stimuli, even to the extent of changing their alarms in response to individual people wearing differently colored shirts (Placer \& Slobodchikoff, 2000; Slobodchikoff et al., 1991). However, much of this specificity is due to different individuals calling during different trials, and accounting for that individual variation reduces or eliminates the information about threat attributes (Loughry, 1987; Loughry Oeser, Anderson et al., 2019).

A later study by Kiriazis and Slobodchikoff (2006) showed that Gunnison's prairie dogs used different escape responses to different predators. The prairie dogs descended into their burrows in response to people or directly-approaching hawks but stood outside the burrow entrance in response to 
coyotes and dogs (Kiriazis \& Slobodchikoff, 2006). Playbacks of alarm calls elicited by hawks, people, coyotes, and dogs elicited these same responses, suggesting that their alarms are functionally referential. No study to date has tested for effects of urgency in Gunnison's prairie dog alarm calls. So, even in this frequently-studied species, much work is needed to clarify the results of previous studies.

\section{Other Prairie Dog Species (Cynomys spp.)}

Black-tailed prairie dogs were tested by Frederiksen and Slobodchikoff (2007) using similar methods to the studies of Gunnison's prairie dogs, and with similar results that suggested calls varied in several parameters predictable by shirt color or a high threat person (firing a gun) versus low threat person (offering food). The remaining three species of prairie dog were likewise tested for effects of shirt color on call structure in Frederiksen's dissertation work (2005). The call parameters that best predicted shirt color varied for each species, or perhaps colony, since one colony was examined per species. However, as Loughry, Oeser \& Hoogland (2019) point out, these results could also be explained by variation in alarm calls due to individual identity of the callers. It is therefore unclear what, if any, information about a potential predator is present in prairie dog alarm calls. These prairie dog studies also highlight the importance of controlling for potential effects of caller attributes, such as individual identity, age, sex, condition and reproductive status, when testing for effects of predator attributes.

\section{Alarms in Xerinae, Tribe Xerini (African Ground Squirrels)}

There are only six species in Xerini, and little work has been done to explore their alarm calls. There is only one study of alarms in the Barbary ground squirrel (Atlantoxerus getulus), which demonstrated that they have functioning alarm calls consisting of a common repeated bark and a rare whistle, which was only observed during an aerial predator attack (van der Marel et al., 2019). Duration of bark did not differ by predator type. The alarm call of the striped ground squirrel (Xerus erythropus) is briefly described as a short repeated bark (Ewer, 1966), but has not been studied further. The Cape ground squirrel (X. inauris) uses two distinct alarm calls (Zumpt, 1970), but their functions and production contexts are unknown. They are known to mob snakes, but unlike the California ground squirrel, they were not observed to vocalize during these events (Phillips \& Waterman, 2014). The mountain ground squirrel (X. princeps), unstriped ground squirrel (X. rutilis), and long-clawed ground squirrel (Spermophilopsis leptodactylus) alarms are undescribed. Experimental studies, or even observational work, investigating alarm calls in Xerini would be beneficial as a comparison to both the burrowing Marmotini and the arboreal Protoxerini.

The selection of ground squirrel species discussed in this review represents the spectrum of ground squirrel alarm systems, from those containing the least to the most information about predator type and characteristics. Information on external context contained in the calls of additional ground squirrel species is found in Table 1. As Table 1 shows, all ground squirrel alarms that have been clearly tested contain information on urgency, and many contain at least some information on whether a threat is aerial or terrestrial, although it is not always clear whether the predator specificity is due to type of predator or urgency of danger, or if there is a distinction.

Studies to disentangle the effects of predator type and urgency on alarm call structure should vary aspects of the threat such as speed, distance, size, or approach angle to create different degrees of urgency within each of two or more predator types (e.g., terrestrial vs. aerial or more taxon-specific types like coyote vs. badger). The data from such studies would clarify the specific effects, if any, of urgency and predator type in shaping alarm call structure. Such production specificity might be categorical by predator type or continuously variable along some axis, much like raptor size affects the number of repetitions of alarm call notes in chickadees (Templeton et al., 2005). The outcomes of such studies would enable tests of whether alarm calls that contain different information on predator context have different effects on conspecific behavior and perhaps on predator behavior. 


\section{Alarm Signals in Tree Squirrels}

Alarm calls in arboreal squirrels have not been studied to the same degree as in ground squirrels. Most work is limited to description of alarm-call repertoires. Studies considering whether arboreal tree squirrel alarm calls contain information on predator type are limited to several observational studies and only a handful of experimental studies (Digweed \& Rendall, 2009, 2010; Greene \& Meagher, 1998). The experimental studies are all in two species, the North American red squirrel (Tamiasciurus hudsonicus) and the gray squirrel (Sciurus carolinensis). Multimodal signaling in sciurid alarms has been looked at only by Partan et al. (2009, 2010), who examined the function of gray squirrels' tail and vocal signals in eliciting alarm behavior in conspecifics, and McRae and Green (2014). Below I review the research to date on specificity of tree squirrel alarm calls. There is no previous work on specificity of tail-signal alarms.

\section{Alarms in Xerinae, Tribe Protoxerini (African Tree Squirrels)}

A search of the literature revealed no experimental studies of alarm calling in any arboreal African squirrels. Most of the existing descriptive work was done by Louise Emmons beginning with her dissertation in 1975, which includes information on alarm calls of arboreal African rainforest squirrels from six genera: Epixerus, Funisciurus, Heliosciurus, Myosciurus, Paraxerus, and Protoxerus. There are not yet quantitative data comparing calls used in various predator contexts to examine predator-specificity or whether risk is encoded. Most species described use multiple acoustically distinct alarm calls and Emmons (1978) classified them into low- and high-intensity alarms, with most species having two lowintensity alarms that were acoustically convergent with other species and a high-intensity alarm that was more species-specific. I will briefly describe the alarm calls of species in each genus and then summarize what we do and do not know about overall patterns in alarm calls of African forest squirrels.

\section{Palm Squirrels (Epixerus)}

Ebian's palm squirrel (E. ebii) uses at least three alarm sounds: (1) soft tooth-chatters audible to people only within a few meters; (2) loud chucks, used infrequently; and (3) very loud, short, broadband staccato barks (Emmons, 1978). Alarm-calling bouts may contain a single vocalization or several repeated calls. Ebian's palm squirrel uses tail signals at the onset of alarm calling, with its tail first hanging straight, then waving laterally a few times (Emmons, 1978).

\section{Rope Squirrels (Funisciurus)}

Rope squirrel alarm-call repertoires seem to vary in size across species, but this variation may be an artifact of how they are classified. Thomas's rope squirrel ( $F$. anerythrus) uses two types of alarm calls: (1) chucks, which are short and have several clear harmonics but vary in length and shape; and (2) whistles and soft notes, which are used together in a bout (Emmons, 1978). Whistles are loud, with only a few harmonics, and are longer than chucks. Soft notes are quiet sounds that seemed to be made during inhalations between whistles (Emmons, 1978). Fire-footed rope squirrels (F. pyrrhopus) used three alarmcall types: (1) chucks, similar to those used by Thomas' rope squirrel but noisier and spanning more frequencies; (2) double chucks, which are quieter chucks in rapid pairs; and (3) staccato calls, which have narrow harmonic bands but are short and repeated rapidly (Emmons, 1978). Ribboned rope squirrels $(F$. lemniscatus) use three call types: (1) chucks, similar to those of Thomas' rope squirrel; (2) double chucks, as above; and (3) pulsed calls of $0.2-0.4 \mathrm{~s}$, highly tonal vocalizations that descend in frequency between pulses (Emmons, 1978). Lady Burton's rope squirrels ( $F$. isabella) use at least two alarm calls: (1) chucks, which can be indistinguishable from those of ribboned rope squirrels; and (2) warbles, a unique call of undulating frequency, resembling linked chucks with less frequency modulation (Emmons, 1978). 
Captive fire-footed, ribboned, and Lady Burton's rope squirrels used chucks (and perhaps double chucks) in response to a preserved snake, which they closely approached and inspected from multiple angles (Emmons, 1975). The same captive species used chucks and tail flicks in response to a perched raptor on the ground but fled when the raptor was moved to a $1 \mathrm{~m}$ perch, and a Lady Burton's rope squirrel began a warble call (Emmons, 1975). A captive Thomas' rope squirrel presented with the same raptor gave a warbling version of its whistle/soft-call vocalizations (Emmons, 1975).

\section{Sun Squirrels (Heliosciurus)}

The red-legged sun squirrel (Heliosciurus rufobrachium) uses two alarm calls: (1) barks, which are variable in frequency but are always very short, broadband calls; and (2) coos, which are longer, narrowband calls that descend in frequency and become pulsed (Emmons, 1978). Emmons (1978) reports that barks were used in response to predators, loud noises, and conspecifics in aggressive interactions. Barks were used in response to a hawk placed outside a red-legged sun squirrel's cage and in response to a caged genet (Emmons, 1975). Coos were used in response to conspecifics placed in the same cage and by free squirrels in response to people (Emmons, 1978). Tail signals were used during alarm calling with the tail bent upwards, and then as each call ended, raised over the back while the squirrel gave a small hop with its hind feet—while keeping its front feet planted (Emmons, 1978).

\section{African Pygmy Squirrels (Myosciurus)}

The African pygmy squirrel (Myosciurus pumilio) has been observed to use only a single alarm call, a soft, repeated "pip," which could not be heard by people beyond a few meters (Emmons, 1978). The squirrels called while continuing to forage vegetation, often positioned on a vertical tree trunk and laterally waving their tails. The alarm call was elicited by people in wild squirrels and not observed otherwise (Emmons, 1978).

\section{Bush Squirrels (Paraxerus)}

The alarms of the red bush squirrels ( $P$. palliatus ornatus and $P$. p. tongensis) include three alarm calls: (1) clicks, which are soft, short, broadband calls usually repeated several times; (2) trills, which are rapid, repetitive narrowband calls; and (3) alarm barks, which are loud, short, broadband calls (Viljoen, 1983). Clicks and trills are also used in nonpredator contexts and seem to play a role in advertising presence to conspecifics (Viljoen, 1983). Clicks are used in association with tail flicking while mobbing people, mongooses, and snakes, including snakes in trees. Viljoen (1983) observed red bush squirrels use barks only in predator contexts, usually to raptors and sometimes when a person appeared suddenly. Playbacks of the alarm bark caused squirrels to alarm bark and flee. Red bush squirrels twitched their tails sporadically while moving and when alarm calling moved their tails in synchrony with clicks. Tail flicks were largest during mobbing behavior (Viljoen, 1983). Interestingly, a related species, Smith's bush squirrels ( $P$. c. cepapi), that lives in savannah rather than forest, usually limits tail signaling to alarm contexts. Although Smith's bush squirrels use similar alarm calls to red bush squirrels, their clicks and barks are higher in pitch, and instead of a trill they use a harsh rattle that extends into higher frequencies than the trill of red bush squirrels (Viljoen, 1983). The lower frequencies used by forest species may be an adaptation to enhance transmission distance in an environment with numerous obstacles (Blumstein, 2007; Viljoen, 1983).

The green bush squirrel (Paraxerus poensis), a rainforest species, used two alarm calls in Emmons' (1978) study. They usually used only one alarm call, a buzz, but twice were heard using a bark similar to the other Paraxerus species. Buzzes slowed over the course of the calling bout and had high dominant frequencies $(5.5 \mathrm{kHz})$ relative to alarm calls of other forest-dwelling Paraxerus species. Buzzes were elicited by people (Emmons, 1978). Emmons $(1975 ; 1978)$ saw no evidence for predator-specific production of alarm calls in the green bush squirrel. 


\section{African Giant Forest Squirrels (Protoxerus)}

The giant forest squirrel (Protoxerus stangeri) uses three alarm calls: (1) a nonvocal, explosive "chuff"; (2) a loud, broadband, vocal bark with lower frequencies than the chuff; and (3) a loud whinny, which is a rapid series of short, narrowband, frequency modulated pulses (Emmons, 1978). There is no apparent predator specificity, but the data are sparse. Whinnies were elicited by raptors and a person in Emmons' (1978) study. Alarm-calling bouts can last for several minutes, longer than most African forest squirrel species. Giant forest squirrels typically use no distinct tail signals while alarm calling but occasionally twitch the tail upwards while moving from place to place during a calling bout (Emmons, 1978).

The fact that most species of African forest squirrels (Protoxerini) use multiple alarm-call types, with production of some alarms being very specific to the presence of a predator while other alarms are also used in social or other contexts, suggests that different alarms may carry different types of information. Based on anecdotal observations of predator presentations to captive squirrels and some observations of wild squirrels responding to predators, Emmons $(1975,1978)$ suggests that alarm calls are not predator specific but differ based on intensity of an internal state of agitation or alarm. Call types used in both social and predator contexts may signal agitation or hostility level, and in an alarm capacity, may signal degree of risk or similar information. The calls used only in the context of a predator could be general alarms or carry more specific information about the nature or urgency of a threat. It is also not certain whether the entire repertoire of alarm calls has been described in some of these species.

Several of the African forest squirrels' calls are structurally similar to alarm calls of North American tree squirrels. African arboreal squirrels are more closely related to North American marmots than to North American tree squirrels (Steppan et al., 2004), but the initial descriptions of African tree squirrels' alarms suggests a convergence of some alarm-call types (Emmons, 1978). Future studies clarifying the production context and function of African forest squirrel alarm calls will enable comparisons of divergence and convergence of alarm-calling systems between two monophyletic groups, the arboreal squirrels of Africa and of the Americas (excluding the neotropical pygmy squirrel, Sciurillus pusillus). A larger monophyletic group contains all ground squirrels (Marmotini and Xerini) and African arboreal squirrels (Herron et al., 2004; Steppan et al., 2004). By comparing alarm calls of ground squirrels, African arboreal squirrels, and New World arboreal squirrels, it may become clear how differences in terrestrial versus arboreal lifestyle and differences in habitat affect the evolution of alarmcalling systems.

\section{Alarms in Callosciurinae (South Asian Tree Squirrels) and Ratufinae (South Asian Giant Squirrels)}

Asian forest squirrels fall into two monophyletic groups, the beautiful squirrels (Callosciurus) and the Asian giant squirrels (Ratufa). The context of Ratufa alarm calling has not been directly studied. The Formosan squirrel (Callosciurus erythraeus thaiwanensis) has at least some degree of production specificity in its alarm calls (Tamura, 1989, 1995; Tamura \& Yong, 1993). The Formosan squirrel used acoustically distinct calls to feral cats, large flying birds, and snakes. The call to feral cats (and rarely other terrestrial animals) began with short, rapidly repeating, broadband barks that slowed down and became longer and more narrowband with several clear harmonics as the call progressed. This pattern resembles that of eastern gray squirrels (Sciurus carolinensis) alarm calls frequently observed in response to feral cats except that the later calls do not become as tonal in the gray squirrel (Lishak, 1984; McRae \& Green, 2014). In the Formosan squirrel, the call to large flying birds was a single vocalization that differed from those given to feral cats (Tamura, 1995). The snake alarm call was a mobbing call, a highpitched scream given when a snake was encountered in a tree, which attracted conspecifics to join the mobbing (Tamura, 1989).

Playbacks of alarm calls elicited by cats caused squirrels to run up trees and remain immobile. Longer alarms resulted in longer immobility (Tamura, 1995). A separate study elicited mobbing calls 
using a stuffed snake placed in trees but did not play back mobbing calls to test effects on conspecifics in the absence of a visible threat. It seems that Formosan squirrels produce predator-specific calls, but it is not clear how these calls affect conspecifics' behavior, especially in the absence of a predator or other visual cues to threat type. Experimental studies directly testing predator specificity are also needed.

Other Callosciurus species may use a similar system to Formosan squirrels. In response to terrestrial threats, the gray-bellied squirrel (Callosciurus caniceps) also uses rapid, staccato, noisy barks that develop clear harmonics as the call continues (Tamura \& Yong, 1993). The plantain squirrel (Callosciurus notatus) and black-banded squirrel (Callosciurus nigrovittatus) also responded to terrestrial threats with staccato barks, but unlike the Formosan and gray-bellied squirrels, their barks in response to terrestrial threats do not change in harmonic structure over the calling bout (Tamura \& Yong, 1993).

Similar to the Formosan squirrel's alarm system, gray-bellied, plantain, and black-banded squirrels all used different vocalizations in response to aerial predators than they used for terrestrial predators, but the call type differed across species. Gray-bellied squirrels use a single low-frequency bark like the Formosan squirrel, whereas plantain squirrels and black-banded squirrels use a low chuckle-a pulsed bark with some harmonic structure (Tamura \& Yong, 1993).

Terrestrial and aerial threats elicited alarm calls and avoidance behavior, but snakes were mobbed. Squirrels of all four Callosciurus species that have been studied gave high-pitched squeaks during mobbing, although chuckles and buzzes were sometimes used when the snake moved (Tamura, 1989; Tamura \& Yong, 1993). Additional squirrels would approach and join the mobbing and calling, which may or may not be due to the squeak calls of mobbing squirrels. Playback experiments could confirm whether squeaks alone are sufficient to attract conspecifics.

The Asian Callosciurus seem to have the most predator-specific alarm vocalizations observed in an arboreal squirrel based on data available to date, but there are no direct tests for association between call types used and stimulus type, although such tests may be possible using data already collected for published studies. Experimental studies to test for predator specificity while controlling other aspects of predator encounters such as distance or speed remain to be done, as well as playbacks comparing response of conspecifics across call types. Interestingly, both Western striped squirrels (Tamiops mcclellandii) and some Calliosciurus species travel with mixed species bird flocks, and western striped squirrels function as sentinels, alarm calling to raptors and reducing bird vigilance (Limparungpatthanakij et al., 2017).

\section{Alarms in Sciurillinae (Neotropical Pygmy Squirrel)}

The neotropical pygmy squirrel (Sciurillus pusillus) is the only species in this subfamily. They are highly vocal, more so than sympatric tree squirrels, vocalizing in over $95 \%$ of observations (Jessen, 2013; Jessen et al., 2013). They have two alarms, a short chirp and a less common trill (Emmons \& Feer, 1997), but no studies have explored their information content or function. They may also be more social than most tree squirrels, as adults have been observed co-nesting in termite nests (Jessen et al., 2013). Given their unique vocal and social behavior and phylogenic positioning relative to sympatric tree squirrels, they offer a unique opportunity to test hypotheses about the evolution of communication systems.

\section{Alarms in Sciurinae (Holarctic and Neotropical Tree Squirrels)}

\section{Eastern gray squirrels (Sciurus carolinensis)}

The eastern gray squirrel uses several alarm call types. Lishak's (1984) descriptive work describes six main alarm call types: (1) buzzes, which are low amplitude buzzing noises audible only within a few meters; (2) kuks, which are broadband barks with sudden onset and ending, often rapidly repeated, with a duration of about $0.1 \mathrm{~s}$; (3) quaas, which have a similar frequency structure to kuks but significantly differ in length (quaas are defined as over $0.15 \mathrm{~s}$ ); (4) moans, which are highly tonal calls 
that have distinct harmonics and fade gradually in amplitude over time; (5) buzz-quaas, which are compound calls of buzzes and quaas; and (6) modulated quaas and quaa-moans, which are broadband calls resembling quaas, but with distinct harmonics during part of the call.

Kuks, quaas and moans contain information on whether a predator is approaching terrestrially or aerially, with rapid kuks and quaas in response to terrestrial threats and slower kuks and moans, or moans alone, in response to aerial threats. Tail signals are also smaller in amplitude in response to aerial predators (McRae \& Green, 2014, 2015). Despite their high information content regarding predator category, it is not exclusive, perhaps partly due to confounding factors in the design (aerial stimuli ended up on the ground and sometimes elicited kuks and quaas). It is also possible that the calls are a result of an emotional state and that this state, while associated with predator type, varies enough to cause overlap in vocalization type.

Gray squirrels respond with different escape behavior in response to aerial versus terrestrial simulated attacks. Simulated hawk attacks resulted in squirrels fleeing to more sheltered locations on the far side of a tree trunk. During simulated cat attacks, they fled to less sheltered locations that maintained a line of sight to the threat (McRae \& Green, 2017). However, when quaas versus moans were played back, squirrels gave the same response to both call types, fleeing to the side of a tree facing the sound source. It appears that the presence of moans versus quaas is insufficient for conspecifics to specialize their response.

Although there is currently no evidence that the information about predator type is used by conspecifics, which could otherwise explain how the calls came to diverge, the presence of information on predator type in the alarm system of gray squirrels could be hypothetically explained by two other, non-exclusive hypotheses. First, perhaps the calls in response to terrestrial threats function partly to discourage an ambush predator, like a cat, from staying in the area after it has been seen. The calls in response to cats resemble mobbing behavior, orienting toward the threat with loud, noisy calls and rapid tail flagging that make the caller easy to locate, which could both help conspecifics increase antipredator behavior (McRae \& Green, 2014; Partan et al., 2009) and possibly deter predators at the same time. Such simultaneous conspecific warning and predator deterrence functions exist for leopard alarms in vervets (Isbell \& Bidner, 2016). Although hawks could potentially face a similar disadvantage once spotted, they are quite capable of successfully capturing a squirrel in a tree, unlike cats. This difference could make a mobbing function in response to aerial threats less effective than in response to terrestrial threats.

Second, if calls by squirrels in a tree to terrestrial predators are less risky than those to aerial predators, callers could minimize their own risk by using less conspicuous alarms in response to aerial predators. This fits with squirrels' flight to more protected locations, reduced tail flagging, reduced kukking, and increased use of narrowband moans in response to aerial threats. Even if calling is simply a result of an emotional state like frustration, there may be strong selection to inhibit that expression when still in danger. Harkening back to the motivational-structural concept (Morton, 1977), both the rapid kuk and quaa alarms and the slow moan alarms could result from high hostility, but with greater fear modifying the alarms into higher-pitched, narrowband calls that are less conspicuous when faced with a threat squirrels cannot as effectively escape.

\section{Red Squirrels (Tamiasciurus hudsonicus)}

Greene and Meagher (1998), working in Montana, conducted the first experimental test for predator-specific alarm calls in an arboreal squirrel, the North American red squirrel (Tamiasciurus hudsonicus). They observed three distinct alarm calls used in response to natural predators, experimental presentations of both a model bird and a live dog: (1) seets, which are low-amplitude, high-frequency sounds similar to alarms used by many small birds; (2) barks, which are loud, explosive calls with broad overtones; and (3) seet-barks, which are acoustically intermediate to seets and barks. Seet-barks start like a seet, add multiple harmonics, and then end with a noisier segment much like a bark (Greene \& Meagher, 1998). 
Green and Meagher (1998) observed seets and seet-barks, but never barks, in response to raptors and ravens. In contrast, barks were the only vocalization used in response to people and dogs, except for one squirrel that produced a seet. They also presented squirrels with a small, colorful, wind-up flying bird model (Amazing TIM model bird, De Ruymbeke Co., Marseille, France), which elicited proportions of seets and seet-barks similar to those used in response to natural encounters with large birds. Initially, this result seems to be a clear case of predator specificity. Although ravens are not typically considered predators of red squirrels, they are of similar size and build to hawks that do feed on squirrels. However, the wind-up flying bird elicited similar responses despite not resembling any predator. Although Greene and Meagher (1998) claim that the model is the general size and shape of a Cooper's hawk, it has only a 12" wingspan, which is from a half to a third that of an adult Cooper's hawk's wingspan (Clark \& Wheeler, 2001; Dunn \& Alderfer, 1999; Vuilleumeir, 2009). It is similar in size to a thrush (Vuilleumeir, 2009), and most models of the toy have color patterns unprecedented in Montana birds. It may be a good object to test squirrels' responses to a novel flying object, but it is not particularly suited to imitating a raptor. The model was flown toward focal squirrels, which could cause it to be viewed as a threat regardless of size or appearance. The fact that it elicited similar responses to raptors at a distance could mean, as Greene and Meagher (1998) propose, that red squirrels classify threats into broad aerial and terrestrial categories.

Alternatively, red squirrels may use different calls to reflect different levels of alarm. This explanation also fits Greene and Meagher's (1998) data. At similar distances, the small model bird may not elicit the same level of alarm as a large, living, terrestrial predator. It is also not clear that distances to terrestrial and aerial predators are similar in their study. The encounters with raptors were rarely closer than $30 \mathrm{~m}$. Of all the large birds, only ravens came within $20 \mathrm{~m}$ of the responding squirrel, and they did so while flying through the area. If all these birds represent only distant and often passing threats, they may elicit lower levels of alarm. It would be interesting to know whether use of seets and seet barks is associated with distance to the large birds or flight status (perched or flying).

Similarly, the consistent use of barks in response to terrestrial predators could reflect a higher level of alarm. The terrestrial predators in the study also differed from aerial predators by approaching more closely and more directly, and perhaps by having their attention focused on the squirrel or their persistence in the area. If these factors do increase level of alarm in red squirrels, then their vocalizations may reflect a gradation from mild (seet) to moderate (seet-bark) to intense (bark) alarm. The red squirrels in Montana used different calls in different contexts, but the relevant difference in context is not yet clear.

The case of the red squirrel is further complicated by the results of Digweed and Rendall's (2009) work, which did not find any predator specificity of alarm-call type. In a Canadian population, Digweed and Rendall (2009) observed only two alarm calls in response to predators, the seet and seet-bark, although barks were heard in other contexts. Since the bark was the terrestrial-predator call in Green and Meagher's (1998) study, the lack of barks in the observations of Digweed and Rendall (2009) makes direct comparison difficult. The red squirrels in Alberta, Canada, used both seets and seet-barks in mixed bouts when responding to terrestrial predators, aerial predators, and martens, which are squirrel-preying specialists capable of pursuing squirrels either terrestrially or arboreally. They also used both call types to nonpredatory species, although less often (Digweed \& Rendall, 2009). During a bout, the most frequent call type shifted from seets to seet-barks. Coyotes elicited a higher proportion of seet-barks and longer calling bouts; these variables are related since the proportion of seet-barks increases as a call continues (Digweed \& Rendall, 2009).

Digweed and Rendall (2010) also conducted playbacks, presenting squirrels with repeated seets, seet-barks, or a natural combination of both calls. They found no effect of call type or call speed (each exemplar was manipulated into a fast and slow version) on squirrels' orientation to the speaker, time spent vigilant, frequency of vigilance, or squirrels' tendency to move a short distance up or down a tree. There was a statistically insignificant trend for pure seets to elicit less vigilance.

Given the difference in bark use between the Montana and Canada studies, studies are needed to clarify the information content and function of red squirrel alarm calls. Playbacks including pure barks would be enlightening as, according to both studies, barks are not produced under the same conditions as 
seet-barks (Digweed \& Rendall, 2009; Greene \& Meagher, 1998). Red squirrels are highly territorial, and their alarm calls are interpreted by Digweed and Rendall (2009) as primarily intruder calls given to both conspecifics and predators entering their territory and primarily directed at the intruder. The calls therefore carry information about the presence of an intruder and may still serve an alarm-call function, as Digweed and Rendall (2010) previously showed that playbacks of seets and seet-barks increased vigilance relative to control sounds. Whether this increased vigilance functions primarily to detect conspecifics or predators is an open question. Playbacks of red squirrel alarm calls to predators to test whether the alarm calls of the red squirrel have a predator-deterrence function would be helpful.

\section{Effects of Caller Attributes on Alarms}

Although predator attributes can affect alarm calls, alarm calls are also affected by attributes of the caller. Many studies of squirrel alarms have noted cues to a caller's individual identity in properties of their alarm calls (Blumstein \& Daniel, 2004; Blumstein et al., 2004; Digweed et al., 2012; Hare \& Atkins, 2001; Loughry, Oeser \& Hoogland, 2019). At least some species of squirrels respond to this identity information by varying their response depending on the caller, sometimes based on the caller's reliability (Blumstein \& Daniel, 2004; Hare, 1998; Hare \& Atkins, 2001). However, this identity information may be stable only over specific time spans. Yellow ground squirrels were observed to have alarm calls with cues to individual identity that were reliable within years, but not across years, due to significant changes in alarm call structure after hibernation (Matrosova et al., 2010). Similarly, speckled ground squirrels (Matrosova et al., 2009) and European ground squirrels (Schneiderová et al., 2017) were found to have alarms whose individually-specific structure changed over time, but changed slowly enough that it might not inhibit recognition of callers on a daily basis and would not inhibit discrimination of distinct callers even if identity was unknown.

If not allowed for, this variation between individual callers can confound the interpretation of variability associated with predator attributes, as in Gunnison's prairie dogs described previously. Having as few as one trial per caller led to observations of call variation associated with predator attributes, when in fact call variation was due to having different callers, each with an individually distinct call- the association with predator attributes disappeared when caller identity was controlled for (Loughry Oeser, Anderson et al., 2019; Loughry, Oeser,\& Hoogland, 2019). There are also effects of age, condition, sex, and reproductive status on some squirrel alarm calls, which can vary by species and can sometimes affect conspecific response (Blumstein \& Daniel, 2004; Brandler et al., 2019; Hoogland, 1983; Matrosova et al., 2011, 2016). Although a thorough discussion of the interactions between effects of caller attributes and predator attributes on alarm call use and structure is beyond the scope of this review, understanding such combined effects in even a few systems could clarify much about the function of alarm calls and their evolution. To avoid entangling the effects of caller and predator on alarm calls, studies should be designed to either use repeated measures of the same known individual under different predator contexts, or at least to use a sufficiently large sample in each experimental group to ensure that effects of individual identity, age, condition and sex on calls are balanced across experimental groups.

\section{Effects of Habitat and Refuge Type on Specificity of Alarms}

Ground squirrel alarm-calling systems vary in number of call types and in receiver response to differing calls (Table 1). In many cases, it seems that alarm calls contain information on urgency rather than predator type directly, yet different predators may tend to present different levels of urgency. An urgency-based alarm system would fit with the hypothesis that ground squirrels have essentially one escape response, so what they are responding to is irrelevant. Knowing how intensely to respond may be more important than knowing the type of predator. Habitat could also shape alarm specificity to communicate urgency over predator type if the lack of visual obstacles in open environments allows squirrels to easily determine predator type once vigilance has been elevated. Ground squirrels do face incompatible options (e.g., run or freeze) when attempting to avoid predation. Even a ground squirrel that 
runs to a burrow opening must decide to retreat down the burrow or stand at the opening, Similarly, any ground squirrel hearing an alarm could stand up on its hind legs and increase its field of view or reduce its profile by staying on all fours. Although some ground squirrels seem to have urgency-based alarm systems, California ground squirrels, that live in burrows in open habitat, have two escape responses and two call types (Leger \& Owings, 1978). Urgency is also independently communicated by amplitude and number of repetitions (Leger et al., 1979). Future studies replicating that work in other species could clarify whether alarm structure and escape response is driven only by urgency, or also differs independently of urgency because of terrestrial versus aerial predator type.

Arboreal squirrels usually retreat to a tree when threatened. This behavior may initially look like a single escape-response, but trees offer more predator-avoidance strategies than most burrows. Retreating down a burrow blocks an occupant's view of anything surrounding the burrow, whereas an animal retreating to a tree may have improved its view of the surrounding area by elevating itself above ground-level visual obstacles. So, a tree could be used as a vantage point as well as being used to block a predator's access to the prey individual.

Trees also differ from burrows in their ability to block terrestrial and aerial predators. A burrow effectively blocks any aerial threat, and only rapidly digging species like badgers pose significant threats to a ground squirrel in a burrow, particularly if the burrow is connected to others or includes an escape tunnel. In contrast, a tree squirrel that flees up a tree from a terrestrial predator is usually safe. With few exceptions, notably martens and related arboreal mustelids (Martes spp.), most mammalian predators have no chance of capturing a tree squirrel in a tree. Further, a squirrel in a tree can often flee through the canopy to neighboring trees without returning to the surface of the ground. Trees thus offer near certain escape from terrestrial threats, similarly to burrows.

When facing aerial threats, the situation is different for ground squirrels and tree squirrels. A raptor cannot hope to pursue a squirrel down a burrow, but many woodland raptors are adept at chasing prey through the canopy and regularly take prey from tree branches (e.g., red-tailed hawks (Barkalow \& Shorten, 1973), goshawks (Widén, 1987; Salafsky \& Reynolds, 2005), Cooper's hawks (Bielefeldt et al., 1992; Meng, 1959). I have seen both red-tailed hawks and Cooper's hawks perform remarkable and lengthy acrobatics in pursuit of gray squirrels. A ground squirrel in a burrow may be losing foraging time, but it is relatively safe from both aerial and terrestrial predators. A tree squirrel in a tree is safe from terrestrial predators but not necessarily from aerial predators. If tree squirrels' arboreal refuge differs in its relative effectiveness against aerial versus terrestrial threats, and ground squirrels' refuge in a burrow is similarly effective to all predators, then tree squirrels may benefit more than ground squirrels from explicitly communicating predator type if predator-specific alarms enable conspecifics to take the appropriate antipredator strategy. This difference may be moderated by the tendency of many ground squirrels to stand at a burrow entrance, trading a small amount of safety for visual information on threats.

In addition to its role in shaping escape responses, habitat may also play a role in the evolution of alarm-calling systems due to the different acoustic properties of different habitats. Daniel and Blumstein (1998) explicitly tested this acoustic adaptation hypothesis in four species of marmots and found no support for it in those systems, although they note that some calls transmitted better than others regardless of habitat and some habitats transmitted all calls better than other habitats. Similarly, a survey of rodent alarm calls, including many non-sciurids, found no effect of habitat openness on frequency or bandwidth (García-Navas \& Blumstein, 2016). In contrast to those results, differing acoustic properties have been suggested to explain differences in dominant frequency between congeneric savannah and forest squirrels (Viljoen, 1983). Similarly, the small alarm-call repertoire of some marmots may be due to habitat structure that degrades details of alarm calls, making call rate a more effective carrier of information than changes in frequency structure (Blumstein \& Daniel, 1997). So, evidence of habitat effects on alarm call structure is mixed in sciurids.

Currently, comparisons of alarm-calling systems between mammals with terrestrial versus arboreal escape-strategies are confounded by the taxa that have been investigated. Most studies of mammals that seek refuge in trees examine primates, and most studies of mammals that seek refuge on or under the ground examine squirrels. It is thus unclear whether any differences observed are due to habitat 
type or due to the many other differences between primate and squirrel taxa (social structure, body size, anatomy, diet, etc.). Tree squirrels offer the opportunity to study multiple arboreal species that are closely related to ground squirrels but occupy similar habitat to the many primates that have been investigated. Tree squirrels thus isolate effects of phylogeny and habitat when comparing alarm-call systems with arboreal primates and ground squirrels, respectively.

\section{Sociality Effects on Predator Specificity of Alarms}

In addition to the role of habitat and associated escape strategies, sociality may affect the type of alarm-calling system used. Blumstein and Armitage (1997b) found that social complexity was correlated with ground squirrels' alarm-call repertoire size (defined as the number of categorical alarm call types that are distinct to human observers), even after controlling for effects of phylogenetic similarity. Their definition of social complexity uses Equation 1 as shown here.

$$
\begin{aligned}
& S C_{\mathrm{d}}=\log \left[\left(H(X)_{\mathrm{t}}\right) T_{\mathrm{nd}}\right] \\
& H(X)=-\sum p(i) \log _{2} p(i)
\end{aligned}
$$

In Equation 1, $T_{\text {nd }}$ is the time to natal dispersal and $H(X)$ comes from the Shannon-Weiner diversity index (Equation 2), which, in this case, considers the proportion of all individuals belonging to various social roles (breeding female, nonbreeding female, dependent offspring, etc.) in a typical group (Blumstein \& Armitage, 1997b). $H(X)$ increases as the number of social roles in a group increases and as the individuals in a group are more evenly distributed across social roles. The simplest sociality in this system is a species that is always solitary. Blumstein and Armitage's (1997b) method is a vast step toward objectively quantifying sociality, but their use of alarm-call repertoire size is probably too simple a measure of alarm system complexity, as they acknowledge. Alarm-call repertoire size may loosely relate to the amount of information available from alarm calls, but a more objective measure of the information about predators that is contained in species' alarm calls is needed. Such a measure of alarmsystem complexity would require playbacks to examine which information in calls is actually used by receivers. Ideally, both categorical differences and continuous variation in response to various alarm-call characteristics should be incorporated into future measures of alarm-system complexity.

Ground squirrels span the range of sociality from solitary to highly social, and there are many studies examining the information content of alarm calls and receivers' responses to differing alarm calls. The information about predators present in alarm calls has been explored to some extent in over $17 \%$ of the 101 ground squirrel species (Figure 1). Tree squirrels also span the range of sociality, but studies of information about predators in their alarm calls exist for less than $4 \%$ of the 184 species (Figure 1). Even for the most-studied species of tree squirrels, the complexity of their alarm calling systems is not well understood. Before it can be determined whether the trend of social complexity correlating with alarmsystem complexity is a general rule across taxa, we need additional studies describing the information about predators contained in the alarm calls of species other than ground squirrels, and continued investigation of ground squirrel alarm systems. Biologically, the most important information for an individual encountering a predator is any information that enables it to select the response that maximizes its fitness. Such information may include predator type (when various predators have distinct hunting methods), distance to a threat, speed and angle of approach, or a more integrated degree of danger, i.e., urgency. Experimental work where specific predator attributes like these are manipulated and presented to the same individuals would clarify which predator attributes do and do not affect alarm calls and would disambiguate effects of predator and caller on call structure.

Understanding the extent to which a species' alarm call structure is and is not shaped by specific predator and caller attributes would help to correctly characterize an alarm system's complexity and degree of information content. Understanding the nuances of that information content can in turn enable tests of hypotheses considering habitat, sociality, and other potential selective forces that drive communications systems to become more complex. For example, when more studies of tree and ground 
squirrel communication present quantified measures of association, if any, between call type and predator type, or correlations between continuous aspects of call structure (rate, pitch, repetitions, etc.) and continuous attributes of predators (speed, distance, etc.) we could then begin to look across species for any effects of social complexity on information complexity. Our understanding of animal communication could similarly benefit from comparative studies of tree and ground squirrels with similar degrees of sociality, to see if there are habitat effects on the amount or type of information in alarm calls.

As we continue into future decades of studying animal communication, squirrels offer interesting comparisons to arboreal or semi-arboreal primates such as vervets and other Paleotropical monkeys that have been the center of much animal communication work in the last 40 years. Our understanding of animal communication in general could be much furthered by exploring the information content of sciurid alarms, and what part of that information affects the behavior of conspecifics, predators, and heterospecific eavesdroppers.

\section{Acknowledgements}

I thank Daniel Blumstein and a second, anonymous reviewer for their insightful and constructive feedback during the review process. Their input is sincerely appreciated.

\section{References}

Balph, D. M., \& Balph, D. F. (1966). Sound communication of Uinta ground squirrels. Journal of Mammalogy, 47, 440-450. https://doi.org/10.2307/1377685

Barbour, M. A., \& Clark, R. W. (2012). Ground squirrel tail-flag displays alter both predatory strike and ambush site selection behaviours of rattlesnakes. Proceedings of the Royal Society of London, Series B: Biological Sciences, 279, 3827-3833. https://doi.org/10.1098/rspb.2012.1112

Barkalow, F. S., \& Shorten, M. (1973). The world of the gray squirrel (1st ed.). J. B. Lippincott Company.

Bielefeldt, J., Rosenfield, R. N., \& Papp, J. M. (1992). Unfounded assumptions about diet of the Cooper's Hawk. The Condor, 94, 427-436. https://doi.org/10.2307/1369215

Blumstein, D. T. (1999). Alarm calling in three species of marmots. Behaviour, 136, 731-757. https://doi.org/10.1163/156853999501540

Blumstein, D. T. (2007). The evolution of alarm communication in rodents: Structure, function, and the puzzle of apparently altruistic calling. In J. O. Wolff \& P. W. Sherman (Eds), Rodent societies-An ecological \& evolutionary perspective (pp. 317-327). The University of Chicago Press.

Blumstein, D. T., \& Armitage, K. B. (1997a). Alarm calling in yellow-bellied marmots: I. The meaning of situationally variable alarm calls. Animal Behaviour, 53, 143-171. https://doi.org/10.1006/anbe.1996.0285

Blumstein, D. T., \& Armitage, K. B. (1997b). Does sociality drive the evolution of communicative complexity? A comparative test with ground-dwelling sciurid alarm calls. American Naturalist, 150, 179-200. https://doi.org/10.1086/286062

Blumstein, D. T., \& Arnold, W. (1995). Situational specificity in alpine-marmot alarm communication. Ethology, 100, 1-13. https://doi.org/10.1111/j.1439-0310.1995.tb00310.x

Blumstein, D. T., \& Daniel, J. C. (1997). Inter- and intraspecific variation in the acoustic habitats of three marmot species. Ethology, 103, 325-338. https://doi.org/10.1111/j.1439-0310.1997.tb00022.x

Blumstein, D. T., \& Daniel, J. C. (2004). Yellow-bellied marmots discriminate between the alarm calls of individuals and are more responsive to calls from juveniles. Animal Behaviour, 68, 1257-1265. https://doi.org/10.1016/j.anbehav.2003.12.024

Blumstein, D. T., Verneyre, L., \& Daniel, J. C. (2004). Reliability and the adaptive utility of discrimination among alarm callers. Proceedings of the Royal Society of London, Series B: Biological Sciences, 271, 1851-1857.

Boellstorff, D. E., \& Owings, D. H. (1995). Home range, population structure, and spatial organization of California ground squirrels. Journal of Mammalogy, 76, 551-561. https://doi.org/10.2307/1382363

Boero, D. L. (1992). Alarm calling in alpine marmot (Marmota marmota L.): Evidence for semantic communication. Ethology Ecology \& Evolution, 4, 125-138. https://doi.org/10.1080/08927014.1992.9525334

Bonenfant, M. (1996). Escape and vocal responses of eastern chipmunks, Tamias striatus, to simulated aerial predator attack [Unpublished master's thesis]. McGill University.

Brandler, O. V, Tukhbatullin, A. R., \& Nikol'skii, A. A. (2019). Comparative analysis of the alarm call in different 
age and sexual groups of the russet ground squirrel (Spermophilus major) Pallas 1778. Russian Journal of Developmental Biology, 50, 173-179. https://doi.org/10.1134/S1062360419040027

Burke da Silva, K. (1993). Antipredator calling by the eastern chipmunk, Tamias striatus. Master's thesis, McGill University, Montreal. ProQuest Dissertations and Theses.

Burke da Silva, K., Kramer, D. L., \& Weary, D. M. (1994). Context-specific alarm calls of the eastern chipmunk, Tamias striatus. Canadian Journal of Zoology, 73, 1087-1092. https://doi.org/10.1139/z94-146

Clark, W. S., \& Wheeler, B. K. (2001). Field guide to hawks of North America (2nd ed.). Houghton Mifflin Harcourt.

Coss, R. G., McCowan, B., \& Ramakrishnan, U. (2007). Threat-related acoustical differences in alarm calls by wild bonnet macaques (Macaca radiata) elicited by python and leopard models. Ethology, 113, 352-367. https://doi.org/10.1111/j.1439-0310.2007.01336.x

Coss, R. G., \& Owings, D. H. (1977). Snake mobbing by California ground squirrels: Adaptive variation and ontogeny. Behaviour, 62, 50-68. https://doi.org/10.1163/156853977x00045

Daniel, J. C., \& Blumstein, D. T. (1998). A test of the acoustic adaptation hypothesis in four species of marmots. Animal Behaviour, 56, 1517-1528. https://doi.org/10.1006/anbe.1998.0929

Darwin, C. (1872). The expression of emotion in man and animals. John Murray.

Davis, L. S. (1984). Alarm calling in Richardson's ground squirrel (Spermophilus richardsonii). Zeitschrift Für Tierpsychologie, 66, 152-164. https://doi.org/10.1111/j.1439-0310.1984.tb01362.x

Digweed, S. M. (2009). Predator-associated vocalizations in North American red squirrels (Tamiasciurus hudsonicus): To whom are alarm calls addressed and how do they function? Ethology, 115, 1190-1199. https://doi.org/10.1111/j.1439-0310.2009.01709.x

Digweed, S. M., \& Rendall, D. (2009). Predator-associated vocalizations in North American red squirrels, Tamiasciurus hudsonicus: Are alarm calls predator specific? Animal Behaviour, 78, 1135-1144. https://doi.org/10.1016/j.anbehav.2009.07.030

Digweed, S. M., \& Rendall, D. (2010). Are the alarm calls of North American red squirrels (Tamiasciurus hudsonicus) functionally referential? Behaviour, 147, 1201-1218. https://doi.org/10.1163/000579510X513239

Digweed, S. M., Rendall, D., \& Imbeau, T. (2012). Who's your neighbor? Acoustic cues to individual identity in red squirrel Tamiasciurus hudsonicus rattle calls. Current Zoology, 103(5), 758-764. https://doi.org/10.1093/czoolo/58.5.758

Dunn, J. L., \& Alderfer, J. (1999). National geographic field guide to the birds of North America (2nd ed.). National Geographic.

Emmons, L. H. (1975). Ecology and behavior of African rainforest squirrels [Unpublished doctoral dissertation]. Cornell University.

Emmons, L. H. (1978). Sound communication among African rainforest squirrels. Zeitschrift Für Tierpsychologie, 49, 1-49. https://doi.org/10.1111/j.1439-0310.1978.tb01821.x

Emmons, L. H., \& Feer, F. (1997). Neotropical rainforest mammals: A field guide. University of Chicago Press.

Ewer, R. F. (1966). Juvenile behaviour in the African ground squirrel, Xerus erythropus (E. Geoff.). Zeitschrift Für Tierpsychologie, 23, 190-216. https://doi.org/10.1111/j.1439-0310.1966.tb01599.x

Fichtel, C., \& Kappeler, P. M. (2002). Anti-predator behavior of group-living Malagasy primates: Mixed evidence for a referential alarm call system. Behavioral Ecology, 51, 262-275. https://doi.org/10.1007/s00265-0010436-0

Fischer, J. (1998). Barbary macaques categorize shrill barks into two call types. Animal Behaviour, 55, 799-807. https://doi.org/10.1006/anbe.1997.0663

Fischer, J., Hammerschmidt, K., Cheney, D. L., \& Seyfarth, R. M. (2001). Acoustic features of female chacma baboon barks. Ethology, 107, 33-54. https://doi.org/10.1046/j.1439-0310.2001.00630.x

Fischer, J., Hammerschmidt, K., \& Todt, D. (1995). Factors affecting acoustic variation in Barbary-macaque (Macaca sylvanus) disturbance calls. Ethology, 101, 51-66. https://doi.org/10.1111/j.14390310.1995.tb00345.x

Frederiksen, K. (2005). A comparative analysis of alarm calls across the five species of North American prairie dogs [Unpublished doctoral dissertation]. Northern Arizona University.

Frederiksen, J. K., \& Slobodchikoff, C. N. (2007). Referential specificity in the alarm calls of the black-tailed prairie dog. Ethology Ecology \& Evolution, 19, 87-99. https://doi.org/10.1080/08927014.2007.9522569

Furrer, R. D., \& Manser, M. B. (2009). The evolution of urgency-based and functionally referential alarm calls in ground-dwelling species. The American Naturalist, 173, 400-410. https://doi.org/10.1086/596541

García-Navas, V., \& Blumstein, D. T. (2016). The effect of body size and habitat on the evolution of alarm vocalizations in rodents. Biological Journal of the Linnean Society, 118, 745-751. 
https://doi.org/10.1111/bij.12789

Gensini, S. (2020). Aspects of the ongoing debate on animal communication. (Zoo) semiotics and cognitive ethology. In P. A \& F. A (Eds), The extended theory of cognitive creativity. Perspectives in Pragmatics, Philosophy \& Psychology, Vol 23 (pp. 199-216). Springer.

Getty, T. (1981). Territorial behavior of eastern chipmunks (Tamias striatus): Encounter avoidance and spatial timesharing. Ecology, 62, 915-921. http://doi.org/10.2307/1936989

Greene, E., \& Meagher, T. (1998). Red squirrels, Tamiasciurus hudsonicus, produce predator-class specific alarm calls. Animal Behaviour, 55, 511-518. https://doi.org/10.1006/anbe.1997.0620

Hare, J. F. (1998). Juvenile Richardson's ground squirrels, Spermophilus richardsonii, discriminate among individual alarm callers. Animal Behaviour, 55, 451-460. https://doi.org/10.1006/anbe.1997.0613

Hare, J. I. F., \& Atkins, B. A. (2001). The squirrel that cried wolf: Reliability detection by juvenile Richardson's ground squirrels (Spermophilus richardsonii). Behavioral Ecology and Sociobiology, 51, 108-112. https://doi.org/doi101007/s002650100414

Harris, M. A., Murie, J. O., \& Duncan, J. A. (2010). Responses of Columbian ground squirrels to playback of recorded calls. Zeitschrift Für Tierpsychologie, 63, 318-330. https://doi.org/10.1111/j.14390310.1983.tb00747.x

Herron, M. D., Castoe, T. A., \& Parkinson, C. L. (2004). Sciurid phylogeny and the paraphyly of Holarctic ground squirrels (Spermophilus). Molecular Phylogenetics and Evolution, 31, 1015-1030. https://doi.org/10.1016/j.ympev.2003.09.015

Hoogland, J. L. (1983). Nepotism and alarm calling in the black-tailed prairie dog (Cynomys ludovicianus). Animal Behaviour, 31, 472-479. https://doi.org/10.1016/S0003-3472(83)80068-2

Isbell, L. A., \& Bidner, L. R. (2016). Vervet monkey (Chlorocebus pygerythrus) alarm calls to leopards (Panthera pardus) function as a predator deterrent. Behaviour, 153, 591-606. https://doi.org/10.1163/1568539X00003365

Jessen, R. R. (2013). Behavior and ecology of neotropical tree squirrels in seasonally flooded forests in the Peruvian Amazon item type text [Master's thesis, University of Arizona]. https://doi.org/10150/293536

Jessen, R. R., Palmer, G. H., \& Koprowski, J. L. (2013). Neotropical pygmy squirrels (Sciurillus pusillus) share termite nests. Ecotropica, 19, 73-76.

Kirchhof, J., \& Hammerschmidt, K. (2006). Functionally referential alarm calls in tamarins (Saguinus fuscicollis and Saguinus mystax) - Evidence from playback experiments. Ethology, 112, 346-354. https://doi.org/10.1111/j.1439-0310.2006.01165.x

Kiriazis, J., \& Slobodchikoff, C. N. (2006). Perceptual specificity in the alarm calls of Gunnison's prairie dogs. Behavioural Processes, 73, 29-35. https://doi.org/10.1016/j.beproc.2006.01.015

Komarova, S. E., Formozov, N. A., Brandler, O. V., \& Nikol'skii, A. A. (2014). Unusual use of two types of alarm call by the long-tailed ground squirrel (Spermophilus undulatus, Rodentia, Sciuridae). Zoologicheskii Zhurnal, 93, 901-905. https://doi.org/10.7868/S0044513414070095

Krenz, M. C. (1977). Vocalization of the rock squirrel Spermophilus variegatus [Unpublished master's thesis]. Texas Tech University.

Leger, D. W., Berney-Key, S. D., \& Sherman, P. W. (1984). Vocalizations of Belding's ground squirrels (Spermophilus beldingi). Animal Behaviour, 32, 753-764. https://doi.org/10.1016/S0003-3472(84)80151-7

Leger, D. W., \& Owings, D. H. (1978). Responses to alarm calls by California ground squirrels: Effects of call structure and maternal status. Behavioral Ecology and Sociobiology, 3, 177-186. https://doi.org/10.1007/BF00294989

Leger, D. W., Owings, D. H., \& Boal, L. M. (1979). Contextual information and differential responses to alarm whistles in california ground squirrels. Zeitschrift Für Tierpsychologie, 49, 142-155. https://doi.org/10.1111/j.1439-0310.1979.tb00283.x

Lilly, M. V., Lucore, E. C., \& Tarvin, K. A. (2019). Eavesdropping grey squirrels infer safety from bird chatter. PLOS ONE, 14, e0221279. https://doi.org/10.1371/journal.pone.0221279

Limparungpatthanakij, W., Gale, G. A., Brockelman, W. Y., \& Round, P. D. (2017). Western striped squirrel Tamiops mcclellandii: A non-avian sentinel species of bird waves. Raffles Bulletin of Zoology, 65, 474-481.

Lishak, R. S. (1984). Alarm vocalizations of adult gray squirrels. Journal of Mammalogy, 65, 681-684. https://doi.org/10.2307/1380852

Loughry, W. J., Oeser, M., Anderson, C. D., \& Hoogland, J. L. (2019). The importance of individual variation in the alarm calls of Gunnison's prairie dogs. Animal Behaviour, 150, 59-68. https://doi.org/10.1016/j.anbehav.2019.01.019

Loughry, W. J., Oeser, M., \& Hoogland, J. (2019). Alarm calls of the same individual vary during a response to the 
same predator in Gunnison's prairie dogs. Canadian Journal of Zoology, 97, 1092-1100

https://doi.org/10.1139/cjz-2019-0064

Macedonia, J. M. (1990). What is communicated in the antipredator calls of lemurs: Evidence from playback experiments with ringtailed and ruffed lemurs. Ethology, 86, 177-190. https://doi.org/10.1111/j.14390310.1990.tb00428.x

Macedonia, J. M., \& Evans, C. S. (1993). Variation among mammalian alarm call systems and the problem of meaning in animal signals. Ethology, 93, 177-197. https://doi.org/10.1111/j.1439-0310.1993.tb00988.x

MacWhirter, R. B. B. (1992). Vocal and escape responses of Columbian ground squirrels to simulated terrestrial and aerial predator attacks. Ethology, 91, 311-325. https://doi.org/10.1111/j.1439-0310.1992.tb00872.x

Magrath, R. D., Pitcher, B. J., \& Gardner, J. L. (2009). An avian eavesdropping network: Alarm signal reliability and heterospecific response. Behavioral Ecology, 20, 745-752. https://doi.org/10.1093/beheco/arp055

Manser, M. B. (2001). The acoustic structure of suricates' alarm calls varies with predator type and the level of response urgency. Proceedings of the Royal Society of London, Series B: Biological Sciences, 268, 23152324. https://doi.org/10.1098/rspb.2001.1773

Manser, M. B. (2013). Semantic communication in vervet monkeys and other animals. Animal Behaviour, 86, 491496. https://doi.org/10.1016/j.anbehav.2013.07.006

Manser, M. B., Bell, M. B., \& Fletcher, L. B. (2001). The information that receivers extract from alarm calls in suricates. Proceedings of the Royal Society of London, Series B: Biological Sciences, 268, 2485-2491. https://doi.org/10.1098/rspb.2001.1772

Mantor, M. A. (2012). Antipredator behavior of California ground squirrels (Otospermophilus beecheyi) [Unpublished doctoral disseratation]. University of California Davis.

Matrosova, V. A., Blumstein, D. T., Volodin, I. A., \& Volodina, E. V. (2011). The potential to encode sex, age, and individual identity in the alarm calls of three species of Marmotinae. Naturwissenschaften, 98, 181-192. https://doi.org/10.1007/s00114-010-0757-9

Matrosova, V. A., Rusin, M. Y., Volodina, E. V., Proyavka, S. V., Savinetskaya, L. E., Shekarova, O. N., Rashevska, H.V., Volodin, I. A. (2016). Genetic and alarm call diversity across scattered populations of speckled ground squirrels (Spermophilus suslicus). Mammalian Biology, 81, 255-265. https://doi.org/10.1016/j.mambio.2016.01.001

Matrosova, V. A., Schneiderová, I., Volodin, I. A., \& Volodina, E. V. (2012). Species-specific and shared features in vocal repertoires of three Eurasian ground squirrels (genus Spermophilus). Acta Theriologica, 57, 65-78. https://doi.org/10.1007/s13364-011-0046-9

Matrosova, V. A., Volodin, I. A., \& Volodina, E. V. (2009). Short-term and long-term individuality in speckled ground squirrel alarm calls. Journal of Mammalogy, 90, 158-166. https://doi.org/10.1644/08-mamm-a-032.1

Matrosova, V. A., Volodin, I. A., Volodina, E. V, Vasilieva, N. A., \& Kochetkova, A. A. (2010). Between-year stability of individual alarm calls in the yellow ground squirrel Spermophilus fulvus. Journal of Mammalogy, 91, 620-627. https://doi.org/10.1644/09-MAMM-A-143.1

McRae, T. R., \& Green, S. M. (2014). Joint tail and vocal alarm signals of gray squirrels (Sciurus carolinensis). Behaviour, 151, 1433-1452. https://doi.org/10.1163/1568539X-00003194

McRae, T. R., \& Green, S. M. (2015). Gray squirrel alarm call composition differs in response to simulated aerial versus terrestrial predator attacks. Ethology Ecology \& Evolution, 9370, 1-10. https://doi.org/10.1080/03949370.2015.1087433

McRae, T. R., \& Green, S. M. (2017). Vocalizations associated with predator-type do not elicit predator-specific escape responses in grey squirrels. Behaviour, 154, 997-1012. https://doi.org/10.1163/1568539X-00003454

Melchior, H. R. (1971). Characteristics of Arctic ground squirrel alarm calls. Oecologia, 7, 184-190. https://doi.org/10.1007/BF00346360

Meng, H. (1959). Food habits of nesting Cooper's hawks and goshawks in New York and Pennsylvania. The Wilson Bulletin, 71, 169-174. https://doi.org/10.2307/4158742

Mercer, J. M., \& Roth, V. L. (2003). The effects of Cenozoic global change on squirrel phylogeny. Science, 299, 1568-1572. https://doi.org/10.1126/science.1079705

Morton, E. S. (1977). On the occurence and significance of motivational-structural rules in some bird and mammal sounds. American Naturalist, 111, 855-869. https://doi.org/10.1086/283219

Nikol'skii, A. A. (2000). Influence of spatial and temporal factors on vocal activity of the steppe marmot, Marmota bobak. Zoologicheskii Zhurnal, 79, 346-347.

Owings, D. H., \& Leger, D. W. (1980). Chatter vocalizations of california ground squirrels: Predator- and socialrole specificity. Zeitschrift Für Tierpsychologie, 184, 163-184. https://doi.org/10.1111/j.14390310.1980.tb01070.x 
Owings, D. H., \& Virginia, R. A. (1978). Alarm calls of California ground squirrels (Spermophilus beecheyi). Zeitschrift Für Tierpsychologie, 46, 58-70. https://doi.org/10.1111/j.1439-0310.1978.tb01438.x

Partan, S. R., Fulmer, A. G., Gounard, M. A. M., \& Redmond, J. E. (2010). Multimodal alarm behavior in urban and rural gray squirrels studied by means of observation and a mechanical robot. Current Zoology, 56, 313-326. https://doi.org/10.1093/czoolo/56.3.313

Partan, S. R., Larco, C. P., \& Owens, M. J. (2009). Wild tree squirrels respond with multisensory enhancement to conspecific robot alarm behaviour. Animal Behaviour, 77, 1127-1135. https://doi.org/10.1016/j.anbehav.2008.12.029

Phillips, M. A., \& Waterman, J. M. (2014). Anti-snake behaviour in a facultative cooperative breeder, the Cape ground squirrel. Behaviour, 151, 1735-1758. https://doi.org/10.1163/1568539X-00003215

Placer, J., \& Slobodchikoff, C. N. (2000). A fuzzy-neural system for identification of species-specific alarm calls of Gunnison's prairie dogs. Behavioural Processes, 52, 1-9. https://doi.org/10.1016/S0376-6357(00)00105-4

Rendall, D., Owren, M. J., \& Ryan, M. J. (2009). What do animal signals mean? Animal Behaviour, 78, $233-240$. https://doi.org/10.1016/j.anbehav.2009.06.007

Robinson, S. R. (1980). Antipredator behaviour and predator recognition in Belding's ground squirrels. Animal Behaviour, 28, 840-852. https://doi.org/10.1016/S0003-3472(80)80144-8

Rundus, A. S., Owings, D. H., Joshi, S. S., Chinn, E., \& Giannini, N. (2007). Ground squirrels use an infrared signal to deter rattlesnake predation. Proceedings of the National Academy of Sciences of the United States of America, 104, 14372-14376. https://doi.org/10.1073/pnas.0702599104

Salafsky, S. R., Reynolds, R. T. (2005). Patterns of temporal variation in goshawk reproduction and prey resources. Journal of Raptor Research, 39, 237-246.

Scarantino, A., \& Clay, Z. (2015). Contextually variable signals can be functionally referential. Animal Behaviour, 100, e1-e8. https://doi.org/10.1016/j.anbehav.2014.08.017

Schel, A. M., Candiotti, A., \& Zuberbühler, K. (2010). Predator-deterring alarm call sequences in Guereza colobus monkeys are meaningful to conspecifics. Animal Behaviour, 80, 799-808. https://doi.org/10.1016/j.anbehav.2010.07.012

Schel, A. M., Tranquilli, S., \& Zuberbühler, K. (2009). The alarm call system of two species of black-and-white colobus monkeys (Colobus polykomos and Colobus guereza). Journal of Comparative Psychology, 123, 136150. https://doi.org/10.1037/a0014280

Schneiderová, I., Volodina, E. V, Matrosova, V. A., \& Volodin, I. A. (2017). One plus one: Binary alarm calls retain individual signature for longer periods than single-note alarms in the European ground squirrel (Spermophilus citellus). Behavioural Processes, 138, 73-81. https://doi.org/10.1016/j.beproc.2017.02.014

Schwagmeyer, P. L. (1980). Alarm calling behavior of the thirteen-lined ground squirrel, Spermophilus tridecemlineatus. Behavioral Ecology and Sociobiology, 7, 195-200. https://doi.org/10.1007/BF00299364

Schwagmeyer, P., \& Brown, C. H. (1981). Conspecific reaction to playback of thirteen-lined ground squirrel vocalizations. Zeitschrift Für Tierpsychologie, 56, 25-32. https://doi.org/10.1111/j.1439-0310.1981.tb01281.x

Seyfarth, R. M., \& Cheney, D. L. (2003). Meaning and emotion in animal vocalizations. Annals of the New York Academy of Sciences, 1000, 32-55. https://doi.org/10.1196/annals.1280.004

Seyfarth, R. M., \& Cheney, D. L. (2016). The origin of meaning in animal signals. Animal Behaviour. https://doi.org/10.1016/j.anbehav.2016.05.020

Seyfarth, R. M., Cheney, D. L., Bergman, T., Fischer, J., Zuberbühler, K., \& Hammerschmidt, K. (2010). The central importance of information in studies of animal communication. Animal Behaviour, 80, 3-8. https://doi.org/10.1016/j.anbehav.2010.04.012

Seyfarth, R. M., Cheney, D. L., \& Marler, P. (1980a). Monkey responses to three different alarm calls: Evidence of predator classification and semantic communication. Science, 210, 801-803. https://doi.org/10.1126/science.7433999

Seyfarth, R. M., Cheney, D. L., \& Marler, P. M. (1980b). Vervet monkey alarm calls: Semantic communication in a free-ranging primate. Animal Behaviour, 28, 1070-1094. https://doi.org/10.1016/S0003-3472(80)80097-2

Sloan, J. L., Wilson, D. R., \& Hare, J. F. (2005). Functional morphology of Richardson's ground squirrel, Spermophilus richardsonii, alarm calls: The meaning of chirps, whistles and chucks. Animal Behaviour, 70, 937-944. https://doi.org/10.1016/j.anbehav.2005.01.013

Slobodchikoff, C. N., Kiriazis, J., Fischer, C., \& Creef, E. (1991). Semantic information distinguishing individual predators in the alarm calls of Gunnison's prairie dogs. Animal Behaviour, 42, 713-719. https://doi.org/10.1016/S0003-3472(05)80117-4

Slobodchikoff, C. N., Paseka, A., \& Verdolin, J. L. (2009). Prairie dog alarm calls encode labels about predator colors. Animal Cognition, 12, 435-439. https://doi.org/10.1007/s10071-008-0203-y 
Steppan, S. J., Storz, B. L., \& Hoffmann, R. S. (2004). Nuclear DNA phylogeny of the squirrels (Mammalia: Rodentia) and the evolution of arboreality from c-myc and RAG1. Molecular Phylogenetics and Evolution, 30, 703-719. https://doi.org/10.1016/S1055-7903(03)00204-5

Struhsaker, T. T. (1967). Auditory communication among vervet monkeys (Cercopithecus aethiops). In S. A. Altmann (Ed), Social communication among primates (pp. 281-324). The University of Chicago Press.

Tamura, N. (1989). Snake-directed mobbing by the Formosan squirrel Callosciurus erythraeus thaiwanensis. Behavioral Ecology and Sociobiology, 24, 175-180. https://doi.org/10.1007/BF00292100

Tamura, N. (1995). Postcopulatory mate guarding by vocalization in the Formosan squirrel. Behavioral Ecology and Sociobiology, 36, 377-386. https://doi.org/10.1007/BF00177333

Tamura, N., Hayashi, F., \& Miyashita, K. (1989). Spacing and kinship in the Formosan squirrel living in different habitats. Oecologia, 79, 344-352. https://doi.org/10.1007/BF00384313

Tamura, N., \& Yong, H.-S. (1993). Vocalizations in response to predators in three species of malaysian Callosciurus (Sciuridae). Journal of Mammalogy, 74, 703. https://doi.org/10.2307/1382292

Templeton, C. N., Greene, E., \& Davis, K. (2005). Allometry of alarm calls: Black-capped chickadees encode information about predator size. Science, 308, 1934-1937. https://doi.org/10.1126/science.1108841

Townsend, S. W., \& Manser, M. B. (2013). Functionally referential communication in mammals: The past, present and the future. Ethology, 119, 1-11. https://doi.org/10.1111/eth.12015

van der Marel, A., López-Darias, M., \& Waterman, J. M. (2019). Group-enhanced predator detection and quality of vigilance in a social ground squirrel. Animal Behaviour, 151, 43-52. https://doi.org/10.1016/j.anbehav.2019.02.017

Viljoen, S. (1983). Communicatory behaviour of southern African tree squirrels, Paraxerus palliatus ornatus, P. $p$. tongensis, P. c. cepapi and Funisciurus congicus. Mammalia, 47, 441-461. https://doi.org/10.1515/mamm.1983.47.4.441

Vuilleumeir, F. (2009). Birds of North America (American Museum of Natural History) (1st ed.). Dorling Kindersly Publishing.

Warkentin, K. J., Keeley, A. T. H., \& Hare, J. F. (2001). Repetitive calls of juvenile Richardson's ground squirrels (Spermophilus richardsonii) communicate response urgency. Canadian Journal of Zoology, 79, 569-573. https://doi.org/10.1139/cjz-79-4-569

Weary, D. M., \& Kramer, D. L. (1995). Response of eastern chipmunks to conspecific alarm calls. Animal Behaviour, 49, 81-93. https://doi.org/10.1016/0003-3472(95)80156-1

Wheeler, B. C. (2010). Production and perception of situationally variable alarm calls in wild tufted capuchin monkeys (Cebus apella nigritus). Behavioral Ecology and Sociobiology, 64, 989-1000. https://doi.org/10.1007/s00265-010-0914-3

Wheeler, B. C., \& Fischer, J. (2012). Functionally referential signals: A promising paradigm whose time has passed. Evolutionary Anthropology, 21, 195-205. https://doi.org/10.1002/evan.21319

Wheeler, B. C., \& Fischer, J. (2015). The blurred boundaries of functional reference: A response to Scarantino \& Clay. Animal Behaviour, 100, 9-13. https://doi.org/10.1016/j.anbehav.2014.11.007

Widén, P. (1987). Goshawk predation during winter, spring and summer in a boreal forest area of central Sweden. Holarctic Ecology, 10, 104-109. https://doi.org/10.1111/j.1600-0587.1987.tb00745.x

Wilson, D. R., \& Hare, J. F. (2004). Ground squirrel uses ultrasonic alarms. Nature, 430, 523. https://doi.org/10.1038/nature02814

Wilson, D. R., \& Hare, J. F. (2006). The adaptive utility of Richardson's ground squirrel (Spermophilus richardsonii) short-range ultrasonic alarm signals. Canadian Journal of Zoology, 84, 1322-1330. https://doi.org/10.1139/z06-120

Zuberbühler, K. (2000). Referential labelling in Diana monkeys. Animal Behaviour, 59, 917-927. https://doi.org/10.1006/anbe.1999.1317

Zuberbühler, K. (2001). Predator-specific alarm calls in Campbell's monkeys, Cercopithecus campbelli. Behavioral Ecology and Sociobiology, 50, 414-422. https://doi.org/10.1007/s002650100383

Zumpt, I. F. (1970). The ground squirrel. African Wild Life, 24, 115-121. 